\title{
Safety of celecoxib and nonselective nonsteroidal anti-inflammatory drugs in juvenile idiopathic arthritis: results of the phase 4 registry
}

Rachel E Sobel ${ }^{1 *}$, Daniel J Lovell ${ }^{2}$, Hermine I Brunner ${ }^{2}$, Jennifer E Weiss ${ }^{3}$, Paula W Morris ${ }^{4}$, Beth S Gottlieb ${ }^{5}$, Elizabeth C Chalom ${ }^{6}$, Lawrence K Jung ${ }^{7}$, Karen B Onel ${ }^{8}$, Lisa Petiniot ${ }^{9}$, Donald P Goldsmith ${ }^{10}$, Kabita Nanda ${ }^{11,12}$, Michael Shishov ${ }^{13}$, Staci Abramsky ${ }^{1}$, James P Young ${ }^{14}$ and Edward H Giannini ${ }^{2}$ for the Pediatric Rheumatology Collaborative Study Group

\begin{abstract}
Background: This study aimed to assess long-term safety and developmental data on juvenile idiopathic arthritis (JIA) patients treated in routine clinical practice with celecoxib or nonselective nonsteroidal anti-inflammatory drugs (nsNSAIDs).

Methods: Children aged $\geq 2$ to $<18$ years with rheumatoid-factor-positive or -negative polyarthritis, persistent or extended oligoarthritis, or systemic arthritis were enrolled into this prospective, observational, multicenter standardof-care registry. Eligible patients were newly or recently prescribed ( $\leq 6$ months) an nsNSAID or celecoxib. Enrolled patients were followed to the end of the study, whether they remained on the original NSAID, switched, or discontinued therapy altogether. All adverse events (AEs) regardless of severity were captured in the database.
\end{abstract}

Results: A total of 274 patients (nsNSAID, $n=219$; celecoxib, $n=55$ ) were observed for 410 patient-years of observation. Naproxen, meloxicam, and nabumetone were the most frequently used nsNSAIDs. At baseline, the celecoxib group was older, had a numerically longer median time since diagnosis, and a numerically higher proportion of patients with a history of gastrointestinal-related NSAID intolerance. AEs reported were those frequently observed with NSAID treatment and were similar across groups (nsNSAIDs: 52.0\%; celecoxib: 52.9\%). Twelve unique patients experienced a total of 18 serious AEs; the most frequent were infections, and none was attributed to NSAID use.

Conclusions: The safety profile of celecoxib and nsNSAIDs appears similar overall. The results from this registry, ongoing pharmacovigilance, and the phase 3 trial that led to the approval of celecoxib for children with JIA provide evidence that the benefit-risk for celecoxib treatment in JIA remains positive.

Trial registration: ClinicalTrials.gov identifier NCT00688545.

Keywords: Celecoxib, Juvenile idiopathic arthritis, NSAIDs, Safety

\section{Background}

Even in this age of targeted biologic therapies such as tumor necrosis factor- $\alpha$ inhibitors, nonsteroidal antiinflammatory drugs (NSAIDs) are integral to the treatment of juvenile idiopathic arthritis (JIA). NSAIDs may be the only therapy required for symptom control in some patients with JIA, and when used as an adjunct to a

\footnotetext{
* Correspondence: Rachel.Sobel@pfizer.com

'Pfizer Inc, 235 East 42nd St, MS\#219-9-1, New York, NY 10017, USA

Full list of author information is available at the end of the article
}

disease-modifying antirheumatic drug (DMARD), clinical responses to NSAID therapy can be quite robust [1-6].

NSAIDs that inhibit both cyclooxygenase (COX)-1 and -2 enzymes (ie, nonselective or nsNSAIDs) are used in a large majority of patients with JIA, although few NSAIDs have been approved for this indication by regulatory agencies. As of 2005, the only nsNSAIDs approved for the treatment of JIA by the US Food and Drug Administration (FDA) were naproxen, ibuprofen, tolmetin, oxaprozin, and meloxicam. Of the COX-2-selective NSAIDs, rofecoxib (Merck) was approved for JIA in 2004; in December 2006 
the FDA approved celecoxib (Pfizer) to treat the signs and symptoms of juvenile rheumatoid arthritis (JRA) in children aged 2-17 years. This approval was based on a double-blind randomized controlled study that compared celecoxib with naproxen in 242 patients over a 12-week period, with a 12-week open-label extension of 202 patients, contributing a total of 100 patient-years (PY) of exposure for celecoxib. The study demonstrated that the efficacy of celecoxib is noninferior to naproxen, with similar safety and tolerability profiles [3].

In late 2004, rofecoxib was voluntarily withdrawn globally due to cardiovascular (CV) safety concerns in adults. In 2005, another selective NSAID, valdecoxib (Pfizer), was also voluntarily withdrawn due to an unfavorable risk profile in adults, which in part related to the occurrence of severe cutaneous adverse reactions. Studies in adults have suggested that users of any NSAID may be at increased risk of $\mathrm{CV}$ outcomes, independent of the degree of selectivity of COX-2 inhibition [7]. The FDA reviewed the available data for all NSAIDs in 2005 and determined that celecoxib's benefits outweighed its risks for appropriate patients.

While children have a very low risk of CV thromboembolic and serious gastrointestinal (GI) events, many patients with JIA will enter adulthood with arthritis and may require NSAID therapy for prolonged periods. Knowledge regarding adverse effects and long-term sequelae of treating children with NSAIDs is limited. The development program for celecoxib was similar to those for other NSAIDs approved for JIA; none of these programs were sufficiently large (median size, 59 patients) nor exposed patients for a long duration (median duration, 12 weeks) to exclude rare or latent effects of treatment.

To address the need for longer-term data from routine clinical practice regarding the safety of these medications in JIA patients and to fulfill a postapproval commitment to the FDA, we conducted the Safety in Idiopathic Arthritis: NSAIDs and Celebrex Evaluation Registry (SINCERE ${ }^{\mathrm{m}}$; ClinicalTrials.gov identifier \#NCT00688545).

SINCERE was a phase 4 observational multicenter registry designed to collect longer-term safety data and measures of development (defined as growth velocity and pubertal maturation) from JIA patients in the United States who were prescribed celecoxib or nsNSAIDs. In consultation with the FDA, the study ended early due to difficulties in celecoxib patient recruitment as a result of an evolving JIA treatment paradigm that shortened the recommended duration of NSAID use, and the very low incidence rate of observed serious adverse events (SAEs).

\section{Methods}

This was a multicenter, single-country (United States), prospective, observational registry of children and adolescents aged $\geq 2$ to $<18$ years treated with celecoxib or nsNSAIDs by the treating rheumatologist for the signs and symptoms of select categories of JIA conducted from 2009-2012. Categories included persistent or extended oligoarthritis, rheumatoid-factor-positive or -negative polyarthritis, or systemic arthritis (without presence of extra-articular features for $\geq 6$ months prior to enrollment) [8]. Enthesitis-related arthritis and psoriatic arthritis subtypes of JIA were excluded from the study population since celecoxib was approved under the older JRA indication. Given the expected recruitment difficulties in this rare disease and the treatment paradigm in which a child's general pediatrician often initially prescribes an NSAID while waiting for further evaluation and, if necessary, referral to a pediatric rheumatologist, we could not restrict the study population to a true inception or new user design. Patients were eligible for participation if they received a prescription for celecoxib or an nsNSAID not more than 6 months prior (a quasi-inception cohort), although previous cumulative exposure to NSAIDs could exceed 6 months. Enrollment was subsequent to the rheumatologist's decision to initiate or change an NSAID.

Registry assessments were performed at baseline, at approximately months 4,8 , and 12 , and twice yearly thereafter. The minimum requested follow-up in the study was 2 years, with a target total sample size of 400 patients, 200 each in the celecoxib and nsNSAID arms.

Data collected included safety information, defined as all adverse events (AEs) and developmental outcomes (height, weight, and age of menarche if appropriate). The Gastrointestinal Scale for Kids (GISSK) instrument [9] served to assess GI tolerability at baseline and to screen for potential GI AEs during follow-up.

The following additional assessments were conducted: the Childhood Health Assessment Questionnaire [10] at baseline; the rheumatologic joint assessment at the initial and final visits, the physician's global assessment of disease activity, and the parent assessment of overall well-being (both measured on an 11-point ordinal scale ranging from $0-10)$ at each visit.

\section{Drug information and supplies}

The choice of study NSAID (celecoxib or nsNSAID), dosage, frequency, and any adjustments thereof were at the treating rheumatologist's discretion. NSAID switches and discontinuations were recorded, and patients remained under follow-up, even if no longer using any NSAID.

\section{Concomitant medications}

Concomitant DMARDs or biologics, or changes in these medications, were permissible as per the clinical judgment of the treating physician. Concurrent treatment with $>1$ NSAID was not allowed, though occasional use of a second nsNSAID or acetaminophen for pain or antipyresis was permitted. 


\section{JIA diagnosis change}

If a patient's new diagnosis was another JIA category (eg, psoriatic arthritis or enthesitis-related arthritis), they remained in the study; the patient was withdrawn if the new diagnosis was another rheumatic or nonrheumatic disease (eg, lupus, fibromyalgia, or cancer).

\section{$A E$ reporting}

An $\mathrm{AE}$ was defined as any untoward medical occurrence in a study patient as assessed by the treating physician. An SAE was defined as any AE that resulted in death, was life-threatening, required hospitalization or prolongation of existing hospitalization, resulted in persistent or significant disability, or resulted in congenital anomaly. Pregnancy in a patient or patient's partner was to be reported as an SAE, even if no AE occurred in the mother or child. The reporting period for all AEs extended from the time the patient provided informed consent through and including 28 calendar days after the last study visit.

\section{Growth velocity and pubertal maturation}

Growth (height and weight) was assessed via chart abstraction for the year prior to enrollment and at each study encounter throughout the registry. Standard age-appropriate growth charts from the US Centers for Disease Control and Prevention [11] were utilized to monitor for important deviations from the norm. Age of menarche was recorded at enrollment or at later study encounter.

\section{Outcomes of interest}

To address concerns about GI and CV safety with NSAIDs, several events of special interest were defined a priori: GI events consisted of ulcers or complications thereof; $\mathrm{CV} / \mathrm{cardiorenal}$ events comprised thromboembolic events or new-onset/worsening hypertension; and new-onset or worsening hypertension could be identified either as an $\mathrm{AE}$ or via a change in antihypertensive drug use such as initiation or an increase in dose. A post hoc composite GI event category was developed to quantify GI tolerability events, namely nausea/vomiting, abdominal pain, and all other GI events.

\section{Confounder and other assessments}

The following factors were collected: demographics (sex, race, age); targeted medical history, with particular attention to GI risk factors; previous history of GI bleeds; NSAID intolerability and other drug-related adverse reactions; presence of hypertension, prior thromboembolic disease, substantial changes in body weight, or other CV risk factors; medications and dosage, and reason for therapy switches or terminations; concomitant medications; and early withdrawal from the registry, including reason.

\section{Study ethics}

The study protocol, informed consent, and assent documentation were reviewed and approved by the institutional review board(s) at each investigational center. The study was conducted in accordance with the Declaration of Helsinki, International Conference of Harmonisation Good Clinical Practice as appropriate, Good Pharmacoepidemiology Practices [12], and local regulatory requirements and laws. The parent or legal guardian of each eligible patient signed informed consent to participate in the registry and a medical release form, and children signed assent as required by the institutional review board(s).

\section{Treatment classification}

Patients who switched NSAID treatments during the study were included in the treatment group that the patient was in at the time the data were observed. Changing from celecoxib to an nsNSAID (or vice versa) was considered a treatment switch, while changing from one nsNSAID to another was not.

Each participant's total exposure time to each medication was calculated for the full study, even if patients switched medications. AEs were grouped in the main analysis according to the NSAID (celecoxib or nsNSAID) utilized at the time of the event, regardless of the initial NSAID treatment at enrollment. The safety analysis set, which was used for all analyses, consisted of all enrolled patients who were prescribed at least 1 dose of any NSAID, regardless of whether it was celecoxib or a nsNSAID.

\section{Statistical hypotheses and analyses}

No a priori hypotheses were formulated for the analysis as the primary intent of the registry was to collect broad longer term safety information within this cohort of NSAID users with JIA. No formal power analyses were conducted because no comparative analyses were performed.

Due to small sample size, incidence rate ratios were not calculated, although incidence rates and $95 \%$ confidence intervals (CIs) around the incidence rates were calculated according to the method of Sahai and Khurshid [13] as adapted for CIs around individual rates. Only descriptive comparisons of baseline characteristics were performed for the study.

Kaplan-Meier analysis was used to display cumulative exposure time on initial NSAID treatment. SAS software (version 9.1, SAS Institute Inc, Cary, NC) was used to perform all analyses.

\section{Results}

Sixteen Pediatric Rheumatology Collaborative Study Group member sites enrolled 274 patients from April 2009 until January 2012. 


\section{Baseline characteristics}

A total of 219 (80\%) patients received an nsNSAID as initial treatment and $55(20 \%)$ received celecoxib (Table 1). The celecoxib group had a numerically higher mean age than the nsNSAID group (10.0 vs. 8.2 years), with a relatively lower proportion in the youngest age group aged $2-5$ years $(14.5 \%$ vs. $35.2 \%)$ and a relatively greater proportion in the oldest adolescent group aged 16-18 years $(14.5 \%$ vs. $5.0 \%)$. Patients in the nsNSAID group had a shorter median duration of disease by almost 8 months. Similar proportions of celecoxib (9.1\%) and nsNSAID (11.9\%) users changed JIA diagnoses over the course of the study.

The nsNSAID and celecoxib groups were similar at baseline for the rheumatologic joint assessment, physician's global assessment of disease activity, and parent/subject assessment of overall well-being (Table 1). Median weight and height were numerically greater in the celecoxib group than in the nsNSAID group, which is consistent with the age difference. The celecoxib group also had numerically worse results than the nsNSAID group at baseline for all components of the Childhood Health Assessment Questionnaire and GISSK. Differences between groups were greatest for the GISSK's mean severity score (celecoxib 21.9, nsNSAID 12.0) and percentages of patients with specific problems, mainly lower stomach pain (celecoxib 29.1\%, other NSAID 15.5\%) and nausea (celecoxib 25.5\%, nsNSAID 14.6\%). Correspondingly, the celecoxib group had a numerically higher proportion of patients with a history of GI-related NSAID intolerance consistent with other baseline assessments of GI conditions.

\section{Drug exposure and PY of observation}

Mean duration of baseline treatment was similar for the nsNSAID and celecoxib groups (12.5 and 11.2 months, respectively). Exposure to baseline treatment was 228.1 PY for nsNSAIDs and 51.3 PY for celecoxib. Analysis of cumulative time of study drug exposure during baseline treatment after study enrollment did not indicate substantial differences between groups in the distribution of time on treatment (Figure 1). In addition, the proportion of patients lost to follow-up over the course of the study was small and equal in both groups (1.8\%, representing 4 patients and 1 patient in the nsNSAID and celecoxib groups, respectively).

Naproxen (47.8\%), meloxicam (17.9\%), and nabumetone (6.6\%) were the most frequently prescribed nsNSAIDs. At the time of study termination, 79 patients (28.8\% of total) had discontinued NSAID treatment, 11 initially treated with celecoxib and 68 initially treated with another NSAID; furthermore, $67.6 \%$ of those on nsNSAIDs and $70.9 \%$ of those on celecoxib were receiving concomitant medications for JIA (DMARDs, biologics, corticosteroids, and analgesics).

NSAID treatments were switched at least once during the study for 19 patients (6.9\% of the total population). There were 225 patients in the nsNSAID group (219 at baseline and 6 switched from celecoxib) and 68 in the celecoxib group (55 at baseline and 13 switched from nsNSAIDs).

The mean observation time was 14.3 months in the nsNSAID group and 12.0 months in the celecoxib group, and 11.3 months for patients whose NSAID therapy was discontinued $\geq 29$ days after last dose of study medication; the medians were generally similar. The study observed patients for a total of 410.2 PY; individual study medication contributions can be found in Table 2. Mean total follow-up time for all patients regardless of treatment group and off-NSAID observation was 18.0 months.

\section{Safety}

As summarized in Table 3, all-causality AEs were reported for similar percentages of patients during nsNSAID and celecoxib treatment $(52.0 \%$ vs. $52.9 \%)$, and during offNSAID observation (46.8\%); the corresponding incidence rates were $43.7,52.9$, and 49.6 per 100 PYs and the mean duration of observation was similar among these groups. Furthermore, the rates of temporary discontinuation were low $(<10.3 \%)$ but numerically more common in the celecoxib group.

Percentages of patients with any AE considered treatment-related were similar with nsNSAID and celecoxib treatment $(21.3 \%$ vs. $19.1 \%$; Table 4$)$. GI disorders were the most frequently reported type of treatmentrelated AE. Other types of treatment-related AEs were reported for $\leq 2.9 \%$ patients during either study treatment; $7.6 \%$ of patients in the off-treatment group reported an $\mathrm{AE}$ considered treatment-related.

SAEs were reported for 9 patients (4.0\%) during nsNSAID treatment, 2 events $(2.9 \%)$ during celecoxib treatment, and 3 events (3.8\%) during off-NSAID observation (Table 5). There were 12 unique patients with SAEs because 2 patients had SAEs during more than 1 treatment/ observation period and were counted twice for this analysis. Infections were the most frequently reported type of SAE. In an analysis by baseline treatment group, the SAE rate/100 PY was 3.0 (95\% CI, 1.1-4.8) for patients started on nsNSAID and 2.6 (95\% CI, 0.0-6.3) for patients started on celecoxib. No SAE was thought to be attributable to the study medications.

Only 2 patients had AEs of special interest (new-onset or worsening hypertension for both) during study treatment (nsNSAID in both cases; Table 2). Two additional AEs of special interest (complications of GI ulcer and new-onset or worsening hypertension) occurred at least 29 days after 
Table 1 Patient demographics and other baseline characteristics

\begin{tabular}{lll}
\hline & $\begin{array}{l}\text { nsNSAID } \\
(\mathbf{n}=\mathbf{2 1 9})\end{array}$ & $\begin{array}{l}\text { Celecoxib } \\
(\mathbf{n}=\mathbf{5 5})\end{array}$ \\
\hline Age, years, mean (SD) & $8.2(4.45)$ & $10.0(4.09)$ \\
Sex, $\mathrm{n}(\%)$ & & \\
Male & $54(24.7)$ & $8(14.5)$ \\
Female & $165(75.3)$ & $47(85.5)$ \\
Race, $\mathrm{n}$ (\%) & & \\
White & $193(88.1)$ & $49(89.1)$ \\
Black & $16(7.3)$ & $5(9.1)$ \\
Asian & $6(2.7)$ & 0 \\
Other & $4(1.8)$ & $1(1.8)$ \\
Ethnicity, n (\%) & & \\
Hispanic or Latino & $19(8.7)$ & $2(3.6)$ \\
Non-Hispanic or Latino & $200(91.3)$ & $53(96.4)$ \\
Body mass index categories, $\mathrm{n}(\%)$ & & \\
Underweight & $10(4.6)$ & $6(10.9)$ \\
Healthy weight & $143(65.3)$ & $36(65.5)$ \\
Overweight & $38(17.4)$ & $8(14.5)$ \\
Obese & $20(9.1)$ & $4(7.3)$ \\
Missing & $8(3.7)$ & $1(1.8)$ \\
Months since JIA diagnosis, & $4.25(0-163.0)$ & $12.10(0.5-173.5)$ \\
median (range) & &
\end{tabular}

median (range)

JIA category, n (\%)

Systemic

Persistent oligoarticular

Extended oligoarticular

Poly RF (-)

Poly RF (+)

Missing

Patients that have discontinued $\geq 1$

NSAID in prior year, ${ }^{a} \mathrm{n}(\%)$

$A E$

Other reasons

Lack of efficacy

Both AE/lack of efficacy

Rheumatologic joint assessment, mean (SD)

$\begin{array}{lll}\text { Number of joints with active arthritis } & 2.9(4.1) & 3.4(5.4) \\ \text { Number of joints with swelling } & 2.7(4.0) & 3.1(5.1) \\ \begin{array}{l}\text { Number of joints with pain on } \\ \text { motion/tenderness }\end{array} & 1.7(3.6) & 2.5(4.3) \\ \begin{array}{l}\text { Number of joints with loss of motion } \\ \text { 1.7 (3.0) }\end{array} & 1.9(3.2)\end{array}$

Table 1 Patient demographics and other baseline characteristics (Continued)

\begin{tabular}{lll}
\hline $\begin{array}{l}\text { Childhood health assessment } \\
\text { questionnaire, median (range) }\end{array}$ & & \\
Functioning (in past week) $^{c}$ & $0.35(0-2.5)$ & $0.44(0-2.5)$ \\
Pain $^{d}$ & $0.45(0-3.0)$ & $0.66(0-2.5)$ \\
Global evaluation $^{\mathrm{e}}$ & $14.00(0-87.0)$ & $16.50(0-97.0)$ \\
$\begin{array}{l}\text { Physician's Global Assessment of } \\
\text { Disease Activity, }{ }^{f} \text { mean (SD) }\end{array}$ & $2.9(2.2)$ & $2.6(2.4)$ \\
$\begin{array}{l}\text { Parent/subject assessment of } \\
\text { overall well being, }{ }^{g} \text { mean (SD) }\end{array}$ & $2.8(2.5)$ & $3.2(2.6)$
\end{tabular}

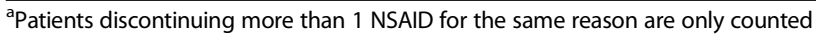
once in the overall summary; however, if a patient discontinued an NSAID for more than 1 reason, the patient contributes to the summary of each of those reasons. ${ }^{b}$ Active arthritis is defined as swelling of the joint or, if no swelling is present, loss of motion accompanied by pain on motion or tenderness. 'Functioning can range from $0-3$, where higher scores indicate more impairment. ${ }^{\mathrm{d}}$ Pain can range from $0-3$, where $0=$ no pain and $3=$ very severe pain.

${ }^{\mathrm{e}} \mathrm{Global}$ evaluation can range from $0-100$, where $0=$ very well and $100=$ very poor.

fPhysician's Global Assessment can range from $0-10$, where $0=$ not active and $10=$ very active.

${ }^{9}$ Parent/subject assessment of overall well-being can range from $0-10$, where $0=$ very well and $10=$ very poorly.

Abbreviations AE: Adverse event, JIA Juvenile idiopathic arthritis, nsNSAID

Nonselective nonsteroidal anti-inflammatory drug, $R F$ Rheumatoid factor.

the study medication (initially treated with celecoxib and nsNSAID, respectively) was stopped.

The incidence rates/100 PY for AEs of special interest during nsNSAID treatment and off-NSAID observation were small $(0.7$ [95\% CI, 0-1.8] and 2.7 [95\% CI, 0-6.4], respectively). Percentages of patients with GI composite $\mathrm{AEs}$ and incidence rates/100 PY of these AEs were generally similar for the nsNSAID and celecoxib groups.

\section{Discussion}

Celecoxib had safety outcomes similar to nsNSAIDs in a total study population of 274 JIA patients followed for a mean duration of approximately 18 months, corresponding to a total of $410 \mathrm{PY}$ of observation. These data add considerably to the body of knowledge regarding NSAID treatment of JIA. The pivotal celecoxib JIA trial [3], one of

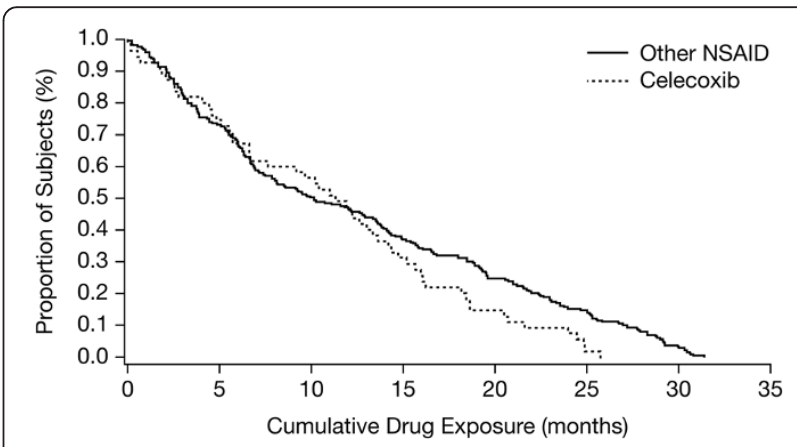

Figure 1 Kaplan-Meier plot comparing cumulative time on baseline study drug. 
Table 2 AEs of special interest and composite gastrointestinal AEs by current treatment group (safety analysis set)

\begin{tabular}{|c|c|c|c|}
\hline Variable/event type/AE ${ }^{a}$ & nsNSAID $\left(n=225^{b}\right)$ & Celecoxib $\left(n=68^{b}\right)$ & Off $\operatorname{NSAID}^{c}(n=79)$ \\
\hline \multicolumn{4}{|l|}{ Incidence, $\mathrm{n}(\%)$} \\
\hline Patients with at least $1 \mathrm{AE}$ of special interest & $2(0.9)$ & 0 & $2(2.5)$ \\
\hline Gl & 0 & 0 & $1(1.3)$ \\
\hline Gl ulcer & 0 & 0 & 0 \\
\hline Complications of Gl ulcer & 0 & 0 & $1(1.3)$ \\
\hline Cardiovascular/cardiorenal & $2(0.9)$ & 0 & $1(1.3)$ \\
\hline Thromboembolic events & 0 & 0 & 0 \\
\hline New-onset or worsening hypertension & $2(0.9)$ & 0 & $1(1.3)$ \\
\hline Patients with at least $1 \mathrm{Gl}$ composite event & $73(32.4)$ & $23(33.8)$ & $17(21.5)$ \\
\hline Abdominal pain & $39(17.3)$ & $12(17.6)$ & $6(7.6)$ \\
\hline Nausea/vomiting & $31(13.8)$ & $13(19.1)$ & $8(10.1)$ \\
\hline All other Gl & $44(19.6)$ & $11(16.2)$ & $11(13.9)$ \\
\hline \multicolumn{4}{|l|}{ Incidence rate (per 100 person-years), $(95 \% \mathrm{Cl})$} \\
\hline Total person-years & 267.6 & 68.0 & 74.6 \\
\hline Incidence rate of events of special interest & $0.7(0-1.8)$ & 0 & $2.7(0-6.4)$ \\
\hline Gl & 0 & 0 & $1.3(0-4.0)$ \\
\hline Gl ulcer & 0 & 0 & 0 \\
\hline Complications of Gl ulcer & 0 & 0 & $1.3(0-4.0)$ \\
\hline Cardiovascular/cardiorenal & $0.7(0-1.8)$ & 0 & $1.3(0-4.0)$ \\
\hline Thromboembolic events & 0 & 0 & 0 \\
\hline New-onset or worsening hypertension & $0.7(0-1.8)$ & 0 & $1.3(0-4.0)$ \\
\hline Incidence rate of Gl composite events & $27.3(21.0-33.5)$ & $33.8(20.0-47.6)$ & $22.8(12.0-33.6)$ \\
\hline Abdominal pain & $14.6(10.0-19.1)$ & $17.6(7.7-27.6)$ & $8.0(1.6-14.5)$ \\
\hline Nausea/vomiting & $11.6(7.5-15.7)$ & $19.1(8.7-29.5)$ & $10.7(3.3-18.2)$ \\
\hline All other Gl & $16.4(11.6-21.3)$ & $16.2(6.6-25.7)$ & $14.7(6.0-23.5)$ \\
\hline
\end{tabular}

aPatients are counted only once in each AE of interest category, and only once in each event type category.

${ }^{\mathrm{b}}$ Patients will appear in both treatment groups if they switched treatments.

'Off NSAID is defined as 29 or more days after last dose of final study medication.

Abbreviations: AE Adverse event, CI Confidence interval GI Gastrointestinal, NSAID Nonsteroidal anti-inflammatory drug.

the largest randomized trials of NSAIDs in JIA, followed patients for $100 \mathrm{PY}$.

The analysis of AEs reported during study treatment generally showed a similar incidence of AEs across groups, and were those that are frequently observed with NSAID treatment (eg, GI-related). Overall, the study results did not indicate a difference in safety profile between celecoxib and other nsNSAIDs. However, the analysis is limited by the study's early termination and reduced sample size as a result. The study would not be able to adequately address the original research question regarding the long-term safety of celecoxib in JIA patients due to

Table 3 Summary of AEs by current treatment group

\begin{tabular}{|c|c|c|c|}
\hline AE category & $\begin{array}{l}\text { nsNSAID }\left(n=225^{a}\right) \\
n(\%)\end{array}$ & $\begin{array}{l}\text { Celecoxib }\left(n=68^{a}\right) \\
n(\%)\end{array}$ & $\begin{array}{l}\text { Off NSAID }^{b}(n=79) \\
n(\%)\end{array}$ \\
\hline Patients with at least $1 \mathrm{AE}$ & $117(52.0)$ & $36(52.9)$ & $37(46.8)$ \\
\hline Patients with at least $1 \mathrm{AE}$ causing temporary discontinuation & $14(6.2)$ & $7(10.3)$ & $2(2.5)$ \\
\hline Patients with at least 1 serious $A E$ & $9(4.0)$ & $2(2.9)$ & $3(3.8)$ \\
\hline Patients with at least $1 \mathrm{AE}$ of special interest & $2(0.9)$ & 0 & $2(2.5)$ \\
\hline Patients with at least $1 \mathrm{Gl}$ composite event ${ }^{c}$ & $73(32.4)$ & $23(33.8)$ & $17(21.5)$ \\
\hline
\end{tabular}

${ }^{a}$ Patients who switch treatments contribute to both treatment groups.

${ }^{b}$ Off NSAID is defined as 29 or more days after last dose of final study medication.

${ }^{c}$ Nausea/vomiting, abdominal pain, or all other $\mathrm{Gl}$.

Abbreviations: AE Adverse event, GI Gastrointestinal, nsNSAID Nonselective nonsteroidal anti-inflammatory drug. 
Table 4 AEs considered treatment-related, by current treatment group

\begin{tabular}{|c|c|c|c|}
\hline MedDRA system organ class/preferred term ${ }^{a}$ & $\begin{array}{l}\text { nsNSAID }\left(n=225^{b}\right) \\
n(\%)\end{array}$ & $\begin{array}{l}\text { Celecoxib }\left(n=68^{b}\right) \\
n(\%)\end{array}$ & $\begin{array}{l}\text { Off NSAID }{ }^{c}(n=79) \\
n(\%)\end{array}$ \\
\hline Patients with at least 1 treatment-related $\mathrm{AE}$ & $48(21.3)$ & $13(19.1)$ & $6(7.6)$ \\
\hline Gl disorders (as shown below) & $36(16.0)$ & $10(14.7)$ & $3(3.8)$ \\
\hline Abdominal pain & $17(7.6)$ & $5(7.4)$ & 0 \\
\hline Nausea & $8(3.6)$ & $3(4.4)$ & $1(1.3)$ \\
\hline Diarrhea & $6(2.7)$ & $2(2.9)$ & 0 \\
\hline Dyspepsia & $5(2.2)$ & $2(2.9)$ & $1(1.3)$ \\
\hline Gastroesophageal reflux disease & $6(2.7)$ & 0 & 0 \\
\hline Constipation & $4(1.8)$ & 0 & $1(1.3)$ \\
\hline Abdominal pain lower & $3(1.3)$ & 0 & 0 \\
\hline Abdominal pain upper & $1(0.4)$ & $2(2.9)$ & 0 \\
\hline Vomiting & 0 & $1(1.5)$ & $1(1.3)$ \\
\hline Abdominal distension & $1(0.4)$ & 0 & 0 \\
\hline Feces discolored & 0 & $1(1.5)$ & 0 \\
\hline Gastritis & $1(0.4)$ & 0 & 0 \\
\hline General disorders and administration site conditions & $3(1.3)$ & 0 & 0 \\
\hline Immune system disorders (drug hypersensitivity) & $1(0.4)$ & 0 & 0 \\
\hline Infections and infestations & $1(0.4)$ & 0 & $1(1.3)$ \\
\hline Injury, poisoning, and procedural complications & $4(1.8)$ & 0 & 0 \\
\hline Investigations & $2(0.9)$ & 0 & 0 \\
\hline Blood pressure increased & $1(0.4)$ & 0 & 0 \\
\hline Blood urea increased & $1(0.4)$ & 0 & 0 \\
\hline Weight decreased & $1(0.4)$ & 0 & 0 \\
\hline Metabolism and nutrition disorders & $5(2.2)$ & $1(1.5)$ & $2(2.5)$ \\
\hline Musculoskeletal and connective tissue disorders & $1(0.4)$ & 0 & 0 \\
\hline Nervous system disorders & $6(2.7)$ & 0 & 0 \\
\hline Renal and urinary disorders & 0 & $2(2.9)$ & 0 \\
\hline Reproductive system and breast disorders & 0 & $1(1.5)$ & 0 \\
\hline Skin and subcutaneous tissue disorders & $4(1.8)$ & 0 & $2(2.5)$ \\
\hline Vascular disorders & $1(0.4)$ & 0 & 0 \\
\hline
\end{tabular}

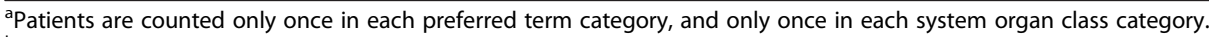

bPatients appear in both treatment groups if they switched treatments.

'Off NSAID is defined as 29 or more days after last dose of final study medication.

Abbreviations: AE Adverse event, MedDRA Medical Dictionary for Regulatory Activities, GI Gastrointestinal, NSAID Nonsteroidal anti-inflammatory drug.

A) difficulties in celecoxib patient recruitment (despite numerous attempts, only $20 \%$ of the $50 \%$ targeted was ever achieved); B) the change in the JIA treatment paradigm that emphasizes NSAID use for relatively short periods of time [14,15], and C) the very low incidence rate of observed SAEs. Furthermore, other accumulating safety data from sources such as the pharmacovigilance database and a simultaneously conducted active surveillance program [16] did not suggest any new signals in the JIA population.

The observational design demonstrated the expected differences between prescribed groups in baseline characteristics and baseline GI risk, indicative of confounding by indication. For example, on study entry, compared with nsNSAID users, the celecoxib users had evidence of more severe JIA disease and longer disease duration, reflecting the use of celecoxib as a second-line (or more) NSAID therapy in JIA. As expected, a history of GI problems and NSAID intolerance was more prevalent in celecoxib users, suggesting that celecoxib was preferentially prescribed by physicians to patients with a demonstrated history of nsNSAID intolerance. Due to the very limited sample size in the celecoxib group, methods such as propensity scores or multivariable regression could not be adequately addressed in analyses. However, based on the above, the study results should provide a conservative estimate 
Table 5 Serious adverse events by current NSAID treatment

\begin{tabular}{|c|c|c|c|c|c|c|}
\hline Patient ID & $\begin{array}{l}\text { Current } \\
\text { medication }\end{array}$ & $\begin{array}{l}\text { Onset-resolution } \\
\left(\text { day }^{\mathrm{a}}\right)\end{array}$ & Reported description & Outcome & $\begin{array}{l}\text { Action taken } \\
\text { (study medication) }\end{array}$ & Causality \\
\hline A & nsNSAID & $729-733$ & Cellulitis & Resolved & No action taken & Other: spider bite \\
\hline B & nsNSAID & $478-481$ & $\begin{array}{l}\text { Benign fibrohistiocytic } \\
\text { lesions with giant cells }\end{array}$ & Resolved & No action taken & Other: idiopathic hip pain \\
\hline C & nsNSAID & $303-307$ & Appendicitis & Resolved & No action taken & Other: appendicitis \\
\hline D & nsNSAID & $27-\mathrm{N} / \mathrm{A}$ & Unintended pregnancy & Unknown & $\begin{array}{l}\text { Permanently } \\
\text { discontinued }\end{array}$ & Other: pregnancy \\
\hline E & nsNSAID & $33-39$ & Meningitis & $\begin{array}{l}\text { Resolved } \\
\text { with sequelae }\end{array}$ & $\begin{array}{l}\text { Permanently } \\
\text { discontinued }\end{array}$ & $\begin{array}{l}\text { Other illness: } \\
\text { infection—probably viral }\end{array}$ \\
\hline $\mathrm{F}$ & nsNSAID & $160-167$ & Fever and neutropenia & $\begin{array}{l}\text { Resolved } \\
\text { with sequelae }\end{array}$ & Stopped temporarily & $\begin{array}{l}\text { Other illness: mycoplasma } \\
\text { infection }\end{array}$ \\
\hline $\mathrm{F}$ & nsNSAID & $161-167$ & Agranulocytosis & $\begin{array}{l}\text { Resolved } \\
\text { with sequelae }\end{array}$ & No action taken & $\begin{array}{l}\text { Other illness: mycoplasma } \\
\text { infection }\end{array}$ \\
\hline G & nsNSAID & $236-288$ & $\begin{array}{l}\text { Infection musculoskeletal } \\
\text { septic arthritis }\end{array}$ & Resolved & Stopped temporarily & Other: unknown \\
\hline $\mathrm{H}$ & nsNSAID & 205-N/A & Onset of systemic JIA & Still present & $\begin{array}{l}\text { Permanently } \\
\text { discontinued }\end{array}$ & Other: systemic JIA \\
\hline । & nsNSAID & $93-149$ & $\begin{array}{l}\text { Right lower quadrant } \\
\text { abdominal pain }\end{array}$ & Resolved & Stopped temporarily & $\begin{array}{l}\text { Other: unknown possible } \\
\text { subclinical appendicitis } \\
\text { but pathology negative }\end{array}$ \\
\hline । & Celecoxib & $138-149$ & Phlegmon & Resolved & Stopped temporarily & $\begin{array}{l}\text { Other: postsurgical } \\
\text { (appendectomy) complication }\end{array}$ \\
\hline । & Celecoxib & 659-N/A & Transformed migraine & Still present & Stopped temporarily & $\begin{array}{l}\text { Other illness: likely related } \\
\text { to past medical history } \\
\text { of migraines }\end{array}$ \\
\hline J & Celecoxib & $82-246$ & Exacerbation of disease & Resolved & No action taken & Disease under study \\
\hline J & Celecoxib & $82-132$ & Fever & Resolved & No action taken & Disease under study \\
\hline K & Off NSAID & $69-\mathrm{N} / \mathrm{A}$ & $\begin{array}{l}\text { Primary sclerosing } \\
\text { cholangitis }\end{array}$ & Still present & $\begin{array}{l}\text { Permanently } \\
\text { discontinued }\end{array}$ & $\begin{array}{l}\text { Other illness: primary } \\
\text { sclerosing cholangitis }\end{array}$ \\
\hline G & Off NSAID & $452-N / A$ & Septic arthritis & Still present & No action taken & $\begin{array}{l}\text { Other illness: septic arthritis } \\
\text { of unknown etiology }\end{array}$ \\
\hline G & Off NSAID & $471-512$ & Acute tubular necrosis & Resolved & $\begin{array}{l}\text { Permanently } \\
\text { discontinued }\end{array}$ & Other: vancomycin \\
\hline L & Off NSAID & $424-429$ & Febrile neutropenia & Resolved & No action taken & $\begin{array}{l}\text { Other illness: infection } \\
\text { questionable Rocky } \\
\text { Mountain spotted fever }\end{array}$ \\
\hline
\end{tabular}

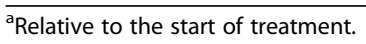

Abbreviations: JIA Juvenile idiopathic arthritis, N/A Not available, nsNSAID Nonselective nonsteroidal anti-inflammatory drug.

of the safety of celecoxib compared with nsNSAIDs. It should be noted that meloxicam, utilized by $18 \%$ of the cohort, exhibits some COX-2-preferential selectivity in some assays; in our analyses, we grouped it with the nsNSAIDs, as the FDA considers it a nonselective NSAID.

SINCERE had numerous strengths. The broad inclusion criteria reflect a more generalizable JIA population than typically participate in randomized clinical trials for drug registration. The demographics and clinical characteristics of the study participants mirror the treated JIA population in the literature [17], suggesting the study is representative of JIA patients in general. Furthermore, the observational design - with treatment assignment decided by the patient's treating rheumatologist-enabled assessment of actual clinical practice and the "real-life" safety profile of
NSAIDs used for this disease. The study was designed a priori to capture detailed information on GI and CV risks and potential confounders to address potential confounding by indication. Despite the early end, this study had very little loss to follow-up for a longer-term observational study (1.8\% in each group), had very little switching across NSAID groups $(<7 \%)$, and recorded much longer mean follow-up time (18 months) than published randomized controlled trials of NSAIDs, which typically had 3-6 months' follow up.

There are several limitations of the registry. Early termination of the study and unexpectedly low celecoxib use in the patient population did not allow for analyses of growth velocity and pubertal maturation or formal comparative safety analyses. Recruitment difficulties causing 
early termination or substantial extensions of enrollment in pediatric studies are a well-known challenge [18-20]. Furthermore, the use of biologics approximately doubled over the course of the study (data not shown) and is consistent with the increasing prevalence of biologic use with associated decline in NSAID use, as demonstrated in a drug utilization study from a large US insurer [21]. The duration of study treatment was relatively short and thus longer-term or latent AEs could not be adequately detected, but this short duration likely reflects actual current clinical practice with NSAIDs [22] in the United States, as suggested by recent guidelines from the American College of Rheumatology on the treatment of JIA $[14,15]$. Extensive use of concomitant medications, especially biologics and DMARDs, was a complicating factor for attribution of observed AEs to study treatment. Selection bias may have occurred; a new-user (NSAID-naïve) design would have minimized this potential bias, but the quasi-inception cohort design was chosen to maximize generalizability and operational efficiency as the number of celecoxib users was anticipated to be substantially less than nsNSAID users. Lastly, as this study was conducted exclusively in the United States, it is unknown whether other regions would have the same findings.

\section{Conclusions}

The safety profile of celecoxib in JIA appears similar overall to that of nsNSAIDs, with few appreciable differences observed in this study. The total study population of 274 patients observed for a total of $410 \mathrm{PY}$ is the largest prospectively followed JIA NSAID cohort to date, and adds considerably to the safety experience of NSAID treatment for JIA. Based on the findings of this study and the low number of SAEs observed overall, no new safety concerns were identified. These registry data, the ongoing pharmacovigilance, and the results of the phase 3 trial that led to the approval of celecoxib for children with JIA further support a positive benefit-risk balance for celecoxib in JIA.

\section{Abbreviations \\ Cl: Confidence interval; COX: Cyclooxygenase; CV: Cardiovascular; DMARD: Disease-modifying antirheumatic drug; FDA: US Food and Drug Administration; Gl: Gastrointestinal; JIA: Juvenile idiopathic arthritis; JRA: Juvenile rheumatoid arthritis; NSAIDs: Nonsteroidal anti-inflammatory drugs; nsNSAIDs: Nonselective NSAIDs; PY: Patient-years.}

\section{Competing interests}

RES and SA are employees and stockholders of Pfizer Inc. DJL has received support and honoraria from Centocor Inc., AstraZeneca, Wyeth Pharmaceuticals, Amgen, Bristol-Myers Squibb, Abbott Immunology Pharmaceuticals, Pfizer Inc., Regeneron, Hoffmann-LaRoche, Inc., Novartis Pharmaceutical Corporation, Forest Laboratories, Horizon Pharmaceuticals. BSG, PWM, and EHG have received support from Pfizer. MS has received honoraria from Abbott, Amgen, Genentech, Novartis, and Pfizer. All other co-authors have no disclosures.

\section{Authors' contributions}

RES conceived the study; RES, SA, EHG, DJL, BSG, and PWM participated in the design, scientific and operational oversight, and interpretation of the study, JPY performed data analysis and interpretation, and EHG and RES drafted the manuscript. All authors except RES, SA, JPY, and EHG contributed to data acquisition. All authors have read and approved the final manuscript.

\section{Authors' information}

Results of this study add further to the growing body of evidence, in a new population of patients, that the safety and tolerability of celecoxib are comparable to that of nonselective NSAIDs. The Pediatric Rheumatology Collaborative Study Group (PRCSG) was founded in 1973 and has more than 150 members at more than 90 academic clinical pediatric rheumatology centers in the United States, Canada, and Puerto Rico. The chief aim of the PRCSG is to conduct high-quality clinical trials of therapeutic agents in children with rheumatic diseases. Activities are overseen by an Advisory Council. DJL is the chairman, HIB is the scientific director, and EHG is the immediate past-senior scientist of the group.

$D J$, HIB, JEW, PWM, BSG, ECC, LKJ, KBO, LP, DPG, KN, and MS are practicing pediatric rheumatologists at academic and/or children's specialty hospitals and hold a number of senior academic and institutional leadership positions. EHG, RES, and SA are experienced pharmacoepidemiologists with additional expertise in conducting pediatric observational studies; RES is also the cofounder and co-chair of the International Society for Pharmacoepidemiology's Special Interest Group in Pediatrics. JPY is a statistician who has worked in pharmaceutical clinical trials for $>10$ years.

\section{Acknowledgements}

This study was sponsored by Pfizer Inc. The authors would like to thank the other investigators who participated in the study: Drs C. Egla Rabinovich, Esi Morgan Dewitt, Marisa S. Klein-Gitelman, Nora G Singer, Philip J Kahn, Natasha Ruth, Thomas Graham, and Adam Reinhardt. We would like to acknowledge the hard work of their site study coordinators; Ms Tameika Graham, Ms Kimberly Petranick, and the staff of UBC for their operational support; Tina Sherrard for her support of the overall study and Shweta Srivastava for data collection; the contributions of Pfizer colleagues such as Drs Sharon Mallen and Sameer Upadhyay; and Drs Margaret Noyes Essex and Robert Reynolds of Pfizer for their critical review of the manuscript. We would also like to offer our heartfelt appreciation to the patients and their parents/guardians for their time and effort to participate in SINCERE. Editorial support was provided by C Campbell, $\mathrm{PhD}$, and $\mathrm{K}$ Bradford, PhD, of PAREXEL, and was funded by Pfizer Inc.

\section{Author details}

${ }^{1}$ Pfizer Inc, 235 East 42nd St, MS\#219-9-1, New York, NY 10017, USA

${ }^{2}$ Cincinnati Children's Hospital Medical Center, Cincinnati, OH, USA.

${ }^{3}$ Hackensack University Medical Center, Hackensack, NJ, USA. ${ }^{4}$ University of Arkansas for Medical Science, Little Rock, AR, USA. ${ }^{5}$ Cohen Children's Medical Center of New York, New Hyde Park, NY, USA. ${ }^{6}$ St. Barnabas Medical Center, Livingston, NJ, USA. ${ }^{7}$ Children's National Medical Center, Washington, DC, USA. ${ }^{8}$ University of Chicago, Chicago, IL, USA. ${ }^{9}$ Specially for Children, Dell Children's Medical Center, Austin, TX, USA. ${ }^{10}$ St. Christopher's Hospital for Children/Drexel College of Medicine, Philadelphia, PA, USA. ${ }^{11}$ Rainbow Babies \& Children's Hospital, Cleveland, OH, USA. ${ }^{12}$ Current address: Seattle Children's Hospital, Seattle, WA, USA. ${ }^{13}$ Phoenix Children's Hospital, Phoenix, AZ, USA. ${ }^{14}$ United BioSource Corporation, Ann Arbor, MI, USA.

Received: 14 May 2014 Accepted: 9 July 2014

Published: 16 July 2014

\section{References}

1. Brunner HI, Kim KN, Ballinger SH, Bowyer SL, Griffin TA, Higgins GC, Mier R, Passo MH, Rennebohm R, Schikler K, Lovell DJ: Current medication choices in juvenile rheumatoid arthritis II-update of a survey performed in 1993. J Clin Rheumatol 2001, 7(5):295-300.

2. Cron RQ, Sharma S, Sherry DD: Current treatment by United States and Canadian pediatric rheumatologists. J Rheumatol 1999, 26(9):2036-2038.

3. Foeldvari I, Szer IS, Zemel LS, Lovell DJ, Giannini EH, Robbins JL, West CR, Steidle G, Krishnaswami S, Bloom BJ: A prospective study comparing celecoxib with naproxen in children with juvenile rheumatoid arthritis. J Rheumatol 2009, 36(1):174-182.

4. Murray KJ, Lovell DJ: Advanced therapy for juvenile arthritis. Best Pract Res Clin Rheumatol 2002, 16(3):361-378.

5. Reiff A, Lovell DJ, Adelsberg JV, Kiss MH, Goodman S, Zavaler MF, Chen PY, Bolognese JA, Cavanaugh P Jr, Reicin AS, Giannini EH: Evaluation of the comparative efficacy and tolerability of rofecoxib and naproxen in 
children and adolescents with juvenile rheumatoid arthritis: a 12-week randomized controlled clinical trial with a 52-week open-label extension. J Rheumatol 2006, 33(5):985-995.

6. Ruperto N, Nikishina I, Pachanov ED, Shachbazian Y, Prieur AM, Mouy R, Joos R, Zulian F, Schwarz R, Artamonova V, Emminger W, Bandeira M, Buoncompagni A, Foeldvari I, Falcini F, Baildam E, Kone-Paut I, Alessio M, Gerloni V, Lenhardt A, Martini A, Hanft G, Sigmund R, Simianer S: A randomized, double-blind clinical trial of two doses of meloxicam compared with naproxen in children with juvenile idiopathic arthritis: short- and long-term efficacy and safety results. Arthritis Rheum 2005, 52(2):563-572.

7. Food and Drug Administration: Memorandum: Analysis and recommendations for agency action regarding non-steroidal anti-inflammatory drugs and cardiovascular risk (Updated 2005). http://www.fda.gov/downloads/Drugs/DrugSafety/PostmarketDrug SafetylnformationforPatientsandProviders/UCM106201.pdf.

8. Petty RE, Southwood TR, Manners P, Baum J, Glass DN, Goldenberg J, He X, Maldonado-Cocco J, Orozco-Alcala J, Prieur AM, Suarez-Almazor ME, Woo P. International League of Associations for Rheumatology classification of juvenile idiopathic arthritis: second revision, Edmonton, 2001. J Rheumatol 2004, 31(2):390-392.

9. Brunner HI, Johnson AL, Barron AC, Passo MH, Griffin TA, Graham TB, Lovell DJ: Gastrointestinal symptoms and their association with health-related quality of life of children with juvenile rheumatoid arthritis: validation of a gastrointestinal symptom questionnaire. J Clin Rheumatol 2005, 11(4):194-204.

10. Singh G, Athreya BH, Fries JF, Goldsmith DP: Measurement of health status in children with juvenile rheumatoid arthritis. Arthritis Rheum 1994, 37(12):1761-1769.

11. Centers for Disease and Control Prevention: 2000 CDC Growth Charts for the United States: Methods and Development (Vital Health and Statistics, series 11, number 246). http://www.cdc.gov/growthcharts/ 2000growthchart-us.pdf.

12. US Department of Health and Human Services, Food and Drug Administration, Center for Drug Evaluation and Research, Center for Biologics Evaluation and Research: Guidance for Industry: Good Pharmacovigilance Practices and Pharmacoepidemiologic Assessment. http://www.fda.gov/downloads/regulatoryinformation/guidances/ ucm126834.pdf

13. Sahai H, Khurshid A: Prospective (Cohort) Studies with Person-Time Data In Statistics in Epidemiology: Methods, Techniques and Applications. New York, NY: CRC Press LLC: 1995:172-174.

14. Beukelman T, Patkar NM, Saag KG, Tolleson-Rinehart S, Cron RQ, DeWitt EM, llowite NT, Kimura Y, Laxer RM, Lovell DJ, Martini A, Rabinovich CE, Ruperto N: 2011 American College of Rheumatology recommendations for the treatment of juvenile idiopathic arthritis: initiation and safety monitoring of therapeutic agents for the treatment of arthritis and systemic features. Arthritis Care Res 2011, 63(4):465-482.

15. Ringold S, Weiss PF, Beukelman T, Dewitt EM, llowite NT, Kimura Y, Laxer RM, Lovell DJ, Nigrovic PA, Robinson AB, Vehe RK: 2013 update of the 2011 American College of Rheumatology recommendations for the treatment of juvenile idiopathic arthritis: recommendations for the medical therapy of children with systemic juvenile idiopathic arthritis and tuberculosis screening among children receiving biologic medications. Arthritis Care Res (Hoboken) 2013, 65(10):1551-1563.

16. Ringold S, Hendrickson A, Wallace C, Sobel R: Adverse events in juvenile idiopathic arthritis: results from the enhanced drug safety surveillance (EDSS) pilot project [abstract]. Arthritis Rheum 2012, 64(S10):493.

17. Andersson Gäre B: Juvenile arthritis - who gets it, where and when? a review of current data on incidence and prevalence. Clin Exp Rheumatol 1999, 17(3):367-374

18. Hoppu K: Patient recruitment-European perspective. Pediatrics 1999, 104(3 Pt 2):623-626.

19. Tishler $\mathrm{CL}$, Reiss NS: Pediatric drug-trial recruitment: enticement without coercion. Pediatrics 2011, 127(5):949-954.

20. Walson PD: Patient recruitment: US perspective. Pediatrics 1999, 104(3 Pt 2):619-622
21. Beukelman T, Xie F, Curtis J: Usage of TNFa inhibitors for the treatment of juvenile idiopathic arthritis: data from a national U.S. administrative claims database [abstract]. Arthritis Rheum 2010, 62:S100-S101.

22. Kochar R, Walsh KM, Jain A, Spalding SJ, Hashkes PJ: Decreased use of non-steroidal anti-inflammatory drugs for the treatment of juvenile idiopathic arthritis in the era of modern aggressive treatment. Rheumatol Int 2012, 32(10):3055-3060

doi:10.1186/1546-0096-12-29

Cite this article as: Sobel et al: Safety of celecoxib and nonselective nonsteroidal anti-inflammatory drugs in juvenile idiopathic arthritis: results of the phase 4 registry. Pediatric Rheumatology 2014 12:29.

\section{Submit your next manuscript to BioMed Central and take full advantage of:}

- Convenient online submission

- Thorough peer review

- No space constraints or color figure charges

- Immediate publication on acceptance

- Inclusion in PubMed, CAS, Scopus and Google Scholar

- Research which is freely available for redistribution

Submit your manuscript at www.biomedcentral.com/submit
Biomed Central 